communicative approach as well as foreign international experience to improve traditional technology of a foreign language education. The adaptation of the foreign experience based on the development of new technologies appears to be reasonable.

$$
* * *
$$

1. Efanova M.E. Modern foreign pedagogical concepts of teaching a foreign language // Electronic scientific journal of the Pedgogicla College \# 18, 2012.

2. Harwood Nigel (2005). What do we want EAP teaching materials for? Journal of English for Academic Purposes, 4: pp.149-161.

3. Fredricka L. Stollera, Bradley Horna, William Grabea, Marin S. Robinson (2006). Evaluative review in materials development. Journal of English for Academic Purposes, 5: pp. 174-192.

4. Karimova L. A. The content and technology of teaching foreign languages in the context of modernization of higher professional schools. Diss....cand. ped sciences. 13.00.01. - Kazan, 2009.

5. Khabarova L.P. Bilingual education in higher education: foreign and domestic experience. // Proceedings of PSPU named V.G. Belinsky. 2011, \#24.

6. Native English. (Methods of English languages teaching). [electronic source] URL: http://www.nativeenglish.ru.

\title{
Kochetkova N.S. \\ Building English proficiency in academic and research-based writing through teaching translation to technical students
}

Samara State Technical University

(Russia, Samara)

doi: $10.18411 / \mathrm{j}-04-2020-61$

idsp: ljournal-04-2020-61

\section{Abstract}

The article discusses the role and didactic potential of word-for-word translation in teaching English for Science and Technology to graduate and postgraduate students of technical universities. It demonstrates how a well-thought-out approach to editing word-forword translation into and out of the target language helps the teacher efficiently integrate the training of students' translation skills with building their linguistic proficiency in writing English (second language) as well as Russian (first language) academic papers and researchbased reports.

Key words: technical students, word-for-word translation, translation skills, translation transformations, foreign language proficiency, academic and research-based papers.

Currently, the problem of training research competence of technical students attracts special attention of the Russian educational community. The necessary and evident conditions for solving this problem are students' research activity and their ability to communicate ideas and research findings in the form of a clearly structured and logically constructed text, not only in the native (Russian), but also in a foreign language, especially English - the main tool of intercultural communication in the field of science and technologies.

However, the analysis of academic English (second language) writings (presentations for student scientific conferences, reports on scientific projects of Master degree students, annotations and abstracts to scientific papers of postgraduate students) reveals an extremely low-level of English proficiency of many writers.

A specific thing about writing academic English texts is that Russian students produce these texts initially in the native (Russian) language, and then translate them into a foreign (English) language. This is because in Russian educational environment, where the primary 
means of communication is the Russian language, students read, think, speak, and write in Russian but not in a foreign language.

Therefore, when presenting the content of the original Russian text in English, a student gets involved in translation activity. The process of translation is associated with significant difficulties, and requires certain skills that are peculiar rather to language than technical specialists. Therefore, teaching and learning these skills appear to be quite necessary for technical students either.

The author's regular work with students' academic texts translated into English shows that the reason for numerous errors in rendering the Russian text in English is a literal translation. Professional translators of scientific and technical literature believe that it is necessary to avoid literal or word-for-word translation. "You need to translate thoughts, not words. It is wrong, it is impossible, it is forbidden to translate word for word!" [1, c. 431]. It makes no sense to object that literal translation is bad. However, training practice shows that a 'bad' literal translation can be quite useful if it is considered not as an end product, but as a draft of the translation, that is, "a kind of a 'billet' that needs to be finished, i.e. edited" [2, p. 4], which is quite impossible without certain translation skills.

The usefulness of translation as a method of teaching a foreign language has always been the subject of debates, and the opinions of teachers on this issue constantly change. For example, up to the middle of the XX century, translation was the main technique in teaching a foreign language, and translation tasks made up half or even most of all language training exercises. However, with the advent of the communicative method in the $60 \mathrm{~s}$ of the last century and its dominant position in language teaching up until now, translation as a device of foreign language teaching practically disappeared from textbook tasks and exercises. Foreign language teachers, specifically in technical universities, saw the need to focus their efforts on developing teaching techniques aimed to build students' abilities in speaking as well as in translation-free reading of foreign language professionally oriented literature. Nevertheless, translation continued to be used but only as a means for conveying the meaning of vocabulary in pre-text exercises or controlling the accuracy in understanding a foreign language text, but not as a tool for teaching foreign language oral and written speech.

In this article, we consider the possibility of improving technical students' performance in academic English writing through building their translation abilities when editing Russian-English word-for-word translation of scientific texts.

The importance of the topic comes from the need to raise the level of academic proficiency of specialists, a key component of which is academic or research-based writing in English as a foreign language.

The main translation skill, as you know, is the ability to find the best translation option. However, to achieve maximum learning outputs, the teacher should first explain to students what a good translation is (as opposed to literal translation) and how to produce it. Since the translation as well as the production of the original (Russian) text is largely a creative and individual process, the teacher inevitably encounters the difficulty of visualizing the instruction material. Our training experience shows that applying to literal translation provides significant advance in solving the problem.

Usually, the translator comes to the best solution while sorting through some intermediate options, which comparison helps in revealing the optimal translation variant. The ability to find the best translation option quickly and efficiently comes from the following fundamental skills [3, c. 253]:

1) the ability to generate various translation options, i.e. the ability to express the same thing in different ways (the ability to rephrase);

2) the ability among a number of candidate translations to see the defective variants and eliminate (transform) them, and 
3) the ability to choose the best variant from a number of acceptable options.

One of the main tools for finding the optimal translation solution is the ability to apply translation transformations, which are necessary to overcome the lingua - ethnical barrier. It is important not only to know the types of transformations, but also to have a clear idea about the degree of their relevance and adequacy. On the one hand, the non-use of transformations where they are necessary (typical for graduates with low level of English proficiency) leads to literal translation. On the other hand, the use of unnecessary radical transformations (typical for graduates and postgraduates with high level of English proficiency trying to avoid the use of Russian English) leads to free translation. Both literal and free translation can significantly distort the meaning and content of the original text. Therefore, it is extremely important to explain to students the need to strive for an adequate translation transformation, which is somewhere between literal and free translation and presents a very significant characteristic of translation quality.

Among strategic guidelines that help avoid going to one extreme or another when performing transformations, translation experts lay special emphasis on the following principles [3, c. 253]:

1. Motivation of transformation: the transformation should come from the need to achieve equal effect of the original (Russian) and target (English) texts on their readers.

2. Minimization (economy) of transformation: from a number of possible transformations, it is preferable to choose the one, which contributes to achieving an equivalent effect on readers due to smaller semantic-structural deviations from the original text.

3. The limitation of the transformation measure: super transformations are unacceptable even if their application is formally justified by the desire to achieve equivalent effect of the original text and the target text on the reader.

Our experience shows that the third principle is important when translating economic or legal, rather than scientific and technical texts where cultural realities are more likely to be absent, and so are the reasons for applying super transformation. Nevertheless, the areas of students' research work reflect things specific to Russian reality (science, technology and industry), so it would be unreasonable to exclude completely the presence of cultural realities in Russian scientific and technical texts. That is why the knowledge of all the principles of observing transformation radical nature and adequacy during translation will be helpful for technical specialists either.

Extremely useful for building all the above abilities seems to be the proper use of literal translation.

In its most general form, literal translation refers to the text produced through a wordfor-word translation [4, p. 156].

However, simply substituting words of the original (Russian) language for the words of the foreign (English) language using the same form and sequence, ignoring elementary grammatical, logical connections and context, due to language asymmetry, will not allow a reader to understand the meaning of the original text.

Therefore, it seems more appropriate to understand literal translation as the rendering of the content of the original text in the target language through minimal lexical and grammatical transformations, without which this rendering is simply impossible. When translating from English into Russian, such transformations include the translation of gerund, attributive groups, infinitive constructions, etc. During Russian to English translation, the use of lexical and grammatical transformations is usually associated with the translation of impersonal and indefinite-personal sentences, some negative and emphatic constructions, participial and attributive clauses, adverbial participles, reflexive verbs, etc. As for the words translation, it seems advisable to focus students only on the accuracy of selecting in the target 
language lexical equivalents from a number of possible ones without taking into account collocations (natural for the target language words' combination) and beauty of style.

We should note that students are very sensitive to criticism of their independently produced written text as well as the linguistic and translation errors made in it, which prevents an adequate assessment of their writing. So, as an instruction material for in-class activities, we suggest using the Russian texts and their word-for-word English translations performed by graduate and postgraduate students of the previous years of study, both Russian texts and their word-for-word translations being used in their original (pre-editorial) version.

The in-class analysis of such a word-for-word translation enables the teacher not only to demonstrate, but also to teach students to see the typical errors made in rendering the original Russian text in a foreign (English) language. Based on our investigations these errors usually include $[5,6]$ :

1) Errors in pre-translation analysis of the original Russian text. Our experience shows that the original (Russian) texts are full of weaknesses, which typically consist in word redundancy, vagueness and confusion of phrases, absence of logical connections between sentences and sentence parts, as well as the presence of pseudoscientific words and cumbersome structures. These shortcomings not only prevent from understanding the original Russian text, but also make it extremely difficult and often impossible to convey its semantic content in the target (English) language.

2) Grammar mistakes caused by misuse of grammatical forms and syntactic construction of the sentence, wrong verb government, incorrect punctuation, etc.

3) Lexical errors caused by confusion of notions resulting in the choice of English words with the wrong meaning, incorrect use of pseudo-international words or "false friends of the translator", wrong collocations, etc.

4) Errors in text-production tools caused by the wrong choice of connecting words that make up the logical and semantic structure of the text; shift of semantic stress and incorrect actual division of the sentence, etc.

Further work with word-for-word translation deals with the analysis and correction of errors caused by typical to the Russian language ways of conveying thoughts. At this stage, students focus on developing their understanding of how to overcome the linguistic-ethnic barrier, and what translation transformations they need to perform in order to meet the requirements of the target language norm, usage, and peculiarities of cultural differences.

By doing this work, it becomes possible to demonstrate to students how the principles underlying translation transformations work:

1) since any further transformation of the word-for-word translation requires justification for overcoming one or another part of the lingua-ethnic barrier, a student gets a clear idea of what the motivation of the transformation is;

2) since transformations are carried out only in places that do not meet the standards of the target language, and the rest of the places that are already successful at the level of the word-for-word translation remain unchanged, it becomes clear what a principle of minimal transformation is;

3) if cultural realities are present in the original text, a collective discussion of the possible ways for their translation into the target language presents a good opportunity to explain what the fundamental limitation of transformation is, and warn students against performing unreasonable transformations.

To sum up, we should note that a well-thought-out approach to word-for-word translation helps the teacher successfully integrate the training of students' translation skills with building their linguistic proficiency in producing written academic and research-based texts in a foreign (English) language. In addition, working with word-for-word translation allows students to correct and further develop universal for all languages skills, such as 
content structuring and text composing, which, of course, improves the quality of academic writing - the main indicator and key component of academic literacy of a modern specialist.

$$
* * *
$$

1. Klimzo B.N. Occupation of a technical translator. About the English language, translation, and translators of scientific and technical literature. 2-nd ed., rev. and enl. Moscow, R. Valent, Publ, 2006. p.508.

2. $\quad$ Slepovich I.S. Translation course. Minsk, "TetraSystems" Publ, 2001. p. 320.

3. Latyshev L.K. Translation technology: a textbook for students of linguistic colleges and departments. 2nd ed., rev. and enl. Moscow, "Academia" Publ, 2005. p.320.

4. Nelubin L.L. Explanatory translation dictionary. 3-d ed. Moscow, "Flinta" Publ, 2003. p.320.

5. Kochetkova N.S., Revina E.V. The prevention and use of language interference when working with professionally oriented foreign language texts // Philological sciences. Issues of theory and practice. 2016. No. 2 (56). P.1. pp.119-122.

6. Kochetkova N.S. Interference-caused problems in developing linguistic competence of students' academic speech in English. - Bulletin of Samara State Technical University. Series "Psychological and Pedagogical Sciences", No. 1 (37) 2018. pp. 86-93. 